\title{
A QUASI-REgULARIST VIEW OF LAWS
}

\author{
NÉLIDA GENTILE \\ University of Buenos Aires, National University of Lomas de Zamora, ARGENTINA \\ nellygentile@gmail.com
}

\begin{abstract}
It will be analyzed some views about laws and highlight certain aspects in each of them that, in our opinion, are to the detriment of their plausibility. The views that we will analyze are the standard regularist conception and the most sophisticated variant known as the Mill-Ramsey-Lewis (MRL) approach, on the one hand, and the necessitarianist versions of David Armstrong and Stephen Mumford, on the other. Finally, we present an alternative proposal that is intermediate between the regularist conception and Mumford's nomological anti-realism. We believe that our proposal successfully avoids the reviewed difficulties and opens a new theoretical space within the dispute over the laws of nature.
\end{abstract}

Keywords: Scientific laws $\bullet$ laws of nature $\bullet$ necessitarism $\bullet$ regularism $\bullet$ quasi-regularism

RECEIVED: $15 / 03 / 2019$

ACCEPTED: 07/08/2019

\section{Introduction}

The problem of natural laws and causation remains current in the philosophical agenda not only because scientific discourse is loaded with references to the laws of nature, but also because scientific research seeks to establish causal relations and, in principle, such relations appear to be closely linked to the manifestation of natural laws. The literature shows a wide range of conceptions about laws and causality that reveals a huge variety of nuances and unsolved problems. In this regard, van Fraassen points out two problems that an adequate theory of laws should solve: the problem of identification and the problem of inference. The first problem is about how to determine what are the criteria to identify laws and how to distinguish between genuine laws and mere regularities or accidental generalizations. The problem of inference, on the other hand, is about how to derive the regularities existing in the world from the laws. van Fraassen also maintains that when considered together, these two problems generate a dilemma: the solution of any of them causes serious difficulties for the solution of the other. Thus, for example, if we assume that we have identified a certain proposition A as a law, given the dictum "All that is necessary is real (actual)", it seems easy to infer that what A affirms is actually the case. But, in order to solve the matter in this way we would have to explain what kind of necessity we are talking about. One could say that the concept of necessity is primitive, but in 
that case she would not have adequately answered the question (van Fraassen 1989, pp.38-9).

The different theorizations proposed about scientific laws can be classified into two groups: Humean conceptions, also called regularist conceptions, and necessitarianist ones. The former fail to offer an elucidation of the concepts of natural law and causation. Necessitarianist conceptions, on the other hand, are not limited in terms of making metaphysical assumptions, but this is precisely why their supporters do not hesitate to postulate the existence of entities that many other authors would not be willing to accept.

In what follows we will briefly analyze some views about laws and highlight certain aspects in each of them that, in our opinion, are to the detriment of their plausibility. The views that we will analyze are the standard regularist conception and the most sophisticated variant known as the Mill-Ramsey-Lewis (MRL) approach (section 2 ), on the one hand, and the necessitarianist versions of David Armstrong (section 3) and Stephen Mumford (section 4), on the other. Finally (section 5), we present an alternative proposal that is intermediate between the regularist conception and Mumford's nomological anti-realism. We believe that our proposal successfully avoids the reviewed difficulties and opens a new theoretical space within the dispute over the laws of nature.

\section{The regularist view of laws, and the MRL view}

The regularist view of laws receives its name by virtue of reducing laws to regularities, and for reducing regularities, in turn, to mere constant conjunctions between phenomena. The relations between these concepts are not exempt from ambiguities and difficulties. ${ }^{1}$ Recall that, according to the standard interpretation of Hume, ${ }^{2}$ there is no reason to believe in the existence of necessary connections in nature, and therefore there is no reason to believe that there are laws in nature. It is in this way that the Humean view of laws faces the problem of identification, since, to the extent that laws are identified with regularities, there is no way to recognize whether we are in the presence of genuine laws (as the necessitarianists understand them), or in the presence of mere constant conjunctions.

In order to offer an adequate answer to this last problem, some supporters of the Humean view formulated a series of criteria to distinguish laws from other legaliform generalizations (Braithwaite 1953, Ramsey 1929, Goodman 1954, Ayer 1963). In order to do this, they have appealed to the fact that laws have confirmatory evidence, allow for precise explanations and predictions, and are capable of withstanding counterfactual conditionals. However, none of these criteria has proved adequate, as rebuttal examples proliferate, in addition to the difficulty raised by the issue of the 
truth conditions of counterfactual conditionals.

The Best Systems view, also known as MRL (after Mill-Ramsey-Lewis), ${ }^{3}$ is a sophisticated variant of the regularist view. It has its "official" point of origin in Counterfactuals (1973), by Lewis, who in turn mentions a 1928 text by Ramsey which states that laws are "consequences of those propositions which we should take as axioms if we knew everything and organized it as simply as possible in a deductive system". However, this proposal has an even more remote precedent in System of Logic, by John Stuart Mill:

According to one mode of expression, the question, What are the laws nature? may be stated thus: What are the fewest and simplest assumptions, which being granted, the whole existing order of nature would result? Another mode of stating it would be thus: What are the fewest general propositions from which all the uniformities which exist in the universe might be deductively inferred? (Mill 1848, pp.189-90)

According to MRL, the regularities that constitute the laws of nature are those that are expressed by the axioms and theorems of the best deductive systems that express our knowledge about the world. The best systems, in turn, are those that establish an adequate balance between the properties of simplicity and strength, or informative content. "Simplicity" refers to the economy of the system - the least amount of propositions - , and "strength" refers to the ability of a theory to account for observations and measurements, i.e., empirical adequacy. But to the extent that simplicity and strength may conflict with each other, MRL seeks a balanced combination of both properties. Lewis puts it this way:

The virtues of simplicity and strength tend to conflict. Simplicity without strength can be had from pure logic, strength without simplicity from (the deductive closure of) an almanac... What we value in a deductive system is a properly balanced combination of simplicity and strength - as much of both as truth and our way of balancing permit. (1973, p.73)

Given that some systematizations may be simpler than others, and some stronger than others, the laws of nature will be those that are expressed by the axioms (and theorems) that are common to all systems that reach a good balance between strength and simplicity.

To the extent that no commitment is made to the existence of natural or physical necessity, MRL retains a Humean spirit, but, at the same time, seems to give an answer to the problem of identification: an isolated proposition cannot qualify as the description of a law of nature, it is such only when it is part of an axiomatized theory that meets the aforementioned requirements. Mere generalizations, unlike laws, are not incorporated into the deductive systems that capture the regularities of the world. But while MRL might solve one of the problems pointed out by van Fraassen, 
we think that, strictly speaking, it does not constitute a conception about the laws of nature. We will substantiate this conclusion in the next section.

\subsection{Scientific laws and laws of nature}

The various criticisms of the MRL approach present in the literature are well-known (Armstrong 1983, van Fraassen 1989, Carroll 1994, Ellis 2002, Psillos 2002). As documented by Ghins (2007), Lewis's criterion is based on the availability of axiomatized theories, but, even in physics, there are not many theories that meet this condition, and others may not even be axiomatizable (p.130). Additionally, it could be the case that the axiomatization that presents the greatest balance between strength and simplicity remains unknown to us, and even if all axiomatizations were available to us the properties of simplicity, strength, and balance could depend on our own interests and practical reasons, without reflecting any aspect of the world (Carroll 1990; 2002).

The MRL view, we believe, represents at most a conception about scientific laws, but in no way a theory about the laws of nature. As already noted, the best deductive systematization that combines simplicity and strength in a balanced fashion might reflect nothing about the world, as Carroll noted: "scientific law" is not equivalent to "law of nature". MRL relies on pragmatical, in a sense subjective factors, without any substrate in the real world. Psillos's modified version of MRL intended to save this aspect, since, according to him, the web-of-laws reflects the objective structure of the world, which is "an objective nomological structure" (2002, p.154). But this ingredient, of course, introduces a marked realist tint that is far removed from the Humean spirit.

\section{Armstrong's view}

During the 1970s, Dretske, Tooley, and Armstrong presented a view of the laws of nature that appeals to universals. The keynote is that laws are conceived as a relation between universals. "All $F s$ are $G s$ " is a law if and only if there is a relation of nomic necessitation $N(F, G)$ between the properties (universals) of being $F$ and of being $G$. The relation between $\mathrm{F}$ and $\mathrm{G}$ is a relation of necessitation but not one of logical necessity. Thus, $N(F, G)$ implies $(x)(F x \supset G x)$ but not vice versa: the fact that each $F$ is a $G$ does not imply that the universal $F$ is in the relation of necessitation with the universal G. According to Armstrong (1983, p.85):

(1) $N(F, G) \rightarrow(x)(F x \supset G x)$

(2) $(x)(F x \supset G x) \nrightarrow N(F, G)$ 
Note that, in Armstrong's opinion, universals are not transcendent, they are not ante rem but in re, they exist only in their instantiations and, consequently, there are no uninstantiated universals. He indicates that this perspective has the advantage, among others, of allowing a clear distinction between genuine laws and mere generalizations, a task which cannot be accomplished with the regularist view of laws. The difference between a mere regularity and a law of nature lies in the relation between universals instantiated in particulars, that is, in the relation of necessitation: $N(F, G)$. Thus, when $F$ is instantiated, $G$ must also be instantiated by virtue of the necessitation relation that exists between $F$ and $G$. As we have already pointed out, the necessitation relation is nomic and not logical, as there are possible worlds in which $F$ does not necessitate $G$.

Now, $N(F, G)$ is in itself a universal instantiated in positive cases, in laws. Nomological statements such as "All metals expand when heated", "All planets move in ellipses", etc., i.e., $N(F, G), N(P, Q)$, etc., are instantiations of the same type: all instances fall under the form $N(\Phi, \Psi)$, where $\Phi$ and $\Psi$ are second-order variables whose relata are first-order properties.

Armstrong explicitly attempts to neutralize the dilemma presented by van Fraassen. In "The Identification Problem and the Inference Problem" (1993) he argues by taking the idea of singular causation as a premise. In the scenario of what happens and of how things are in the world, he says, there are many regularities that are causal sequences, and causal sequences are successions of singular phenomena connecting a token phenomenon with another token phenomenon, for example, that this blow caused this piece of glass to break. But singular sequences instantiate regularities, since singular causations exhibit a pattern in which the same types of causes produce the same types of effects. There is thus an inference going from cases of singular causation to universals: the existence of universals is the best explanation for this samenesses relation. If something is found that, when presenting property $F$, always also presents property $G$, then if all cases of this type of causal pattern are considered, it is natural to think that they instantiate the same pattern of universals. According to Armstrong, the perception of "causers" is epistemically primitive: in cases of singular causation we have direct causal knowledge: we can feel, for example, the pressure that we can exert on a part of our body.

So far, we have nothing more than singular causations and a pattern of regularity in that the same types of causes generate the same types of effects. However, regular succession could demand an explanation. According to Armstrong, one could hypothesize that regularity is such because the fact that something is $F$ leads to the same thing being $G$, that is, there is a causal relation between the universal $F$ and the universal $G$. This would solve the problem of identification: the relation $N(F, G)$ is a causal relation, the same type of relation that is experienced in the experience of singular causal relations, except that it is not a relation between tokens but a relation 
between types, i.e., a relation between universals. Armstrong clarifies that this is not offered as a proof, but merely as a postulation that is recommended by virtue of its explanatory power. In Armstrong's opinion, once the identification problem is solved, so is the problem of inference, because if a certain type of factual states causally produces certain effects, then it follows from this that tokens of the former type of factual states will cause tokens of the same type of effect. ${ }^{4}$ This inference is analytical, or conceptual.

In the same journal issue that contains Armstrong's essay, van Fraassen offers his reply. ${ }^{5}$ However, it is not our aim to confront the respective arguments but, rather, to point out some corollaries that, in our opinion, discredit Armstrong's position. Let us now move on to them.

\subsection{The particularity of universals}

We have seen that, according to Armstrong, universals exist only in their instantiations. There are no uninstantiated universals. The author assumes a moderate realism that gives universals a place, but not as abstract entities existing outside a specific space and time but, on the contrary, as properties that are embodied in things: redness only exists to the extent that there are red things. Likewise, in the world scenario there are not only individuals and properties, but also causal relations between singular events, relations of which we have a type of knowledge that is direct and not inferential. And to the extent that such singular causations can be located within general patterns where the same type of cause $F$ produces the same type of effect $G$, we can infer certain generalizations, such as "All $F s$ are $G s$ ". Likewise, to explain the co-instantiation of universals in general patterns, he appeals to a second-order relation, one between universals, the "relation of necessitation": $N(F, G)$. And this is the point that we are interested in underlining. According to Armstrong, this relation is a causal one, analogous to the relation we experience in singular causal relations; the only difference being that the relation of necessitation is not a relation between tokens, but a relation between types which is postulated and introduced in virtue of its explanatory effectiveness.

We can observe here two movements that go in opposite directions, one up and the other down, mediated by the application of the rule of inference to the best explanation. In the upward direction it is the observation of "causers" that allows us to infer, we could say inductively, the patterns of regularity. Then, by inference to the best explanation, a relation of necessitation is postulated, and, finally, by a downward, analytical movement, it is guaranteed that $N(F, G) \rightarrow(x)(F x \supset G x)$. This is a strange and paradoxical puzzle! Let us see.

We find here at least three different problems that, although related, have different natures. First, as mentioned above, according to Armstrong universals are in- 
stantiated in particulars - this is a long standing position, characteristic of the Aristotelian tradition - and are strictly dependent on particulars. And this dependence is not only epistemic but has a much deeper foundation, it is an ontological dependence: if the particular does not exist then the universal cannot exist. This is a curious and anti-intuitive position that seems to ride between realism and nominalism.

But, on the other hand, regarding the causation of singular events, Armstrong argues, as mentioned above, that causes are observable, that we perceive "causers", and that that is what allows us to establish regularity patterns such as "All $F s$ are Gs". At this point some questions arise. Without entering into Hume's considerations about the impossibility of founding the causal relation in experience, there is something even more basic. It is true that, if we grant certain licenses, in cases such as those illustrated by Armstrong we can say that we have direct knowledge of the causes, that the blow was what caused the glass to break or, at least, that the hitting of the glass was followed by the corresponding break. But, what happens if we consider another kind of situation? Suppose an event of singular causation, the advent of a storm after a sharp decrease in atmospheric pressure. In this case, such a decrease is not observable, at most what we can observe is a modification in the mercury column of a barometer. And if, according to Armstrong's dictum, we inductively formulate the pattern where the same type of cause $F$ supposedly generates the same type of effect $G$, we should state that "The decrease in the mercurial column of a barometer generates storms", which no one would deem the instantiation of a law of nature. Thus, it seems that Armstrong's thesis that we perceive "causers" could be confirmed by certain kinds of phenomena which are very simple facts, but lacks relevance as the basis of the causal laws of science, in which causal relations referring to unobservables are frequently established. In these cases we do not have a procedure to identify the presence of genuine causal relations, so the problem of identification reappears and, to the extent that the ascending path cannot be taken, the circuit is cut and the problem of inference arises again.

Finally, there is another aspect of Armstrong's position that might seem problematic. According to the universalism that he defends, universals only exist in their instantiations, there are no uninstantiated universals. All universals exist within spacetime coordinates. Now, consider, for example, the statement "All combustible substances contain phlogiston". According to Stahl, phlogiston was an igneous principle that was part of all combustible substances and was released when they burned. Does this statement represent a law of nature? If we suppose so, then it should be a law of nature by virtue of being an instantiation of a relation of necessitation existing between the universal "being a combustible substance" and the universal "being phlogiston", since universals can only exist in their instantiations. However, it seems that there is no phlogiston, so there is no particular capable of instantiating the universal "being phlogiston". 
Armstrong could answer that the existence of universals is not equivalent to our beliefs being always right. Thus, in the case of phlogiston, it could be argued that the situation only shows that by virtue of the fallible nature of knowledge, many alleged scientific laws could prove false and, in that case, the alleged universals involved would have been mistakenly considered as such; but this would be a mere epistemic accident of our human condition, not affecting the conception of laws as relations between universals.

However, it seems to us that the appeal to such a defense suffers from a boomerang effect. If, as anti-realists argue, there is no reason to believe that our theories are true or approximately true, or that the entities postulated in those theories exist, then, according to the argument of pessimistic induction, the example of phlogiston would not be an isolated case but, in the words of Laudan, such examples could extend ad nauseam. And if this is so, although in principle Armstrong's proposal would provide us with a criterion capable of identifying laws, in practice it would be of little use, as we would not know how to discriminate a law of nature from a simple mistake of our imagination.

\section{Stephen Mumford's realist lawlessness}

Given the difficulties that we have encountered in Armstrong's doctrine, the realist lawlessness formulated by Mumford seems to offer, in principle, a novel alternative proposal. Let us analyze this position.

In Laws in Nature (2004), Mumford defends a modal realism that avoids any metaphysical commitment to laws. His position is intermediate between, on the one hand, nomological realism - which he identifies with positions such as the DTA theory (named after Armstrong, Tooley, and Dretske), and Brian Ellis's essentialism and, on the other hand, the "deflationary" view accepted by Humeans. In agreement with the nomological realists and against the Humeans, Mumford maintains that there are necessary connections or modal facts in the world, but in opposition to the former and in coincidence with the latter he rejects the thesis that laws exist. Thus, Mumford's realist lawlessness cannot be considered either an anti-realist position nor a position entirely contrary to Hume's doctrine: according to it, it is necessary connections and not laws what is required to explain the world's regularities. Thus, he proposes an ontology in which some of the main things that make up the world, namely its properties, already have a modality, as they feature necessary connections with other properties, and when they are instantiated in the natural objects of the world there is natural necessity.

In order to substantiate his proposal, Mumford presents the idealized form of the argument on which, in his opinion, the different theories about laws rest, and then 
he presents a dilemma to refute it. The so-called "nomological argument" (NA) is as follows:

A. There is a set $S$ of features in the world.

B. There is $S$ because there are laws of nature.

The members of $S$ are phenomena of the world such as regularity, necessity, counterfactuality, invariance, predictability, and so on, which are only possible because there are laws of nature. Thus, laws are taken as the ontological foundation of the regularities that exist in the world. Note that the argument takes the form of an inference to the best explanation that goes from the existence of regularity or order to the existence of real natural laws as the explanation and foundation of regularity or order.

To demonstrate that there are laws in nature, according to the nomological argument, implies showing that there is some feature in reality that would not be there if there were no laws. Laws should be the only things that could provide a base to those features. But, according to Mumford, the DTA theory fails to adequately justify $B$, that is, that there are the members of $S$ because there are laws, as other things different from laws could account for the members of $S$. And, in order to refute nomological realism, Mumford presents a dilemma that he calls "the Central Dilemma": either laws are external with respect to their instances, or they are internal to them. If they are external to their instances, then they cannot govern or determine their instances. If they are internal, they cannot govern or determine their instances. Then, in no case can laws govern their instances.

This argument is based on the assumptions that laws are more than their instances and that they must fulfill the role of government, i.e., they must govern their instances. Thus, a theory of external laws must offer an adequate explanation of how laws relate to the things that they govern. The most plausible explanation, DTA, still has difficulties in explaining this relationship (Mumford 2004, p.158). Indeed, given that laws "are supervenient in the sense that a universal is nothing in addition to its instances, [...] it is highly implausible to suppose that laws could govern something upon which they are supervenient" (Mumford 2004, p.103). Mumford admits that some other externalist theory of laws might, perhaps, avoid this problem, but, anyway, it would face a new difficulty: the entailment of quidditism. In Mumford's opinion, DTA implies quidditism about properties, since once it is admitted that in other possible worlds universals can be nomically related to universals other than those to which they are nomically related in our own world, to maintain that such a universal is the same property $F$ as in our world the only recourse would be to postulate a single essence, or quiddity.

On the other hand, the second horn of the dilemma applies to the so-called reductive theories about laws, in which laws are not primitive elements of the ontology, 
but are instead constructed from other elements and are therefore reducible to them. The question that the dilemma generates is how laws can govern or play a decisive role on things to which they are reduced: "there is an inconsistency in the idea of something determining that to which it is reducible" (Mumford 2004, p.156). If laws are exhausted in their instances, then they cannot fulfill the role of explaining those instances.

According to the dilemma's conclusion, to the extent that laws do not fulfill their purpose, it can then be affirmed that there are no laws in nature. But that does not mean, as the Humeans argue, that there is no necessity in the world. On the contrary, making use of the terminology introduced by Nancy Cartwright, Mumford states that natural necessity depends on the existence of modal properties. In Mumford's opinion, the necessity that exists in nature is de re. ${ }^{6} \mathrm{He}$ distinguishes different sources of de re necessity that are expressed in relations of inclusion, of exclusion, and of production. There are necessary inclusion relations that do not depend on meaning or logical form (they are not analytically necessary), but depend on the nature of the properties involved. Being colored and having a shape, or having a shape and having size are properties between which there is a necessary connection: every colored surface has a shape and there can be no shape without size. There are also necessary exclusion relations, such as being totally red or being totally blue. And there is a third type of de re necessity, the most interesting one in Mumford's opinion, present in dispositions or causal powers. Being soluble and being dissolved are examples of the latter type. Unlike the first two kinds of de re necessity, dispositions or causal powers have a dynamic nature: they are responsible for the changes that occur in particulars. But dispositions or causal powers should not be understood as properties of properties, i.e., second-order properties added to first-order properties.

Then, according to modal realism there are necessary connections in nature, and those connections are absolutely internal to the powers (dispositions) involved. They are not an external element that is added to powers, but internal relations that exist only by virtue of the existence of their relata (Mumford 2004, p.173). Thus, a "natural cluster of powers" is a set of internally connected and instantiated powers in our world.

As Mumford himself acknowledges, his Central Dilemma attacks the same weaknesses that van Fraassen found in the realistic theory of laws, namely the problem of inference and the problem of identification (Mumford 2004, p.197). Consequently, the modal realism advocated by him should, in principle, be free from both difficulties. However, we consider that this is not the case. Let us see why! 


\subsection{Salva veritate}

We have reviewed Mumford's strategy against nomological realism: the Central Dilemma is, in his view, the most powerful argument against the existence of laws in nature. But this is not the most relevant point. That prize is won by the author's intention, in accordance with his alternative proposal, to show that the vacant space left by laws can be occupied by other type of entities, namely dispositions or causal powers. As Psillos argues, Mumford speaks freely of the causal role of properties and replaces the expression "nomic role" with that of "causal role" (Psillos 2006, p.460). If this is so - and it seems to be so by virtue of Mumford's recurring insistence that the function of laws could be fulfilled by something different - it seems that Mumford maintains the structure of the nomological argument. Let us call it $\left[N A_{M}\right]$.

$A_{M}$. There is natural necessity (a member of the set $S_{M}$ ).

$B_{M}$. There is $S_{M}$ because there are causal powers.

Now, following van Fraassen's idea in his critique of the inference to the best explanation argument, we can say that Mumford chose, at most, "the best of the alternatives" within a bad lot. We also believe that the causal powers view is itself trapped under the Central Dilemma. But given that Mumford has already considered this last objection and offered an answer to it, we must explain why, in our judgment, he fails in his attempt to refute the objection.

Because, according to Mumford, causal powers are not external elements but internal relations that exist only by virtue of the existence of their relata, the first horn of the dilemma seems in principle to be avoided. However, if that were the case, then his theory would automatically face the second horn, which, because of the replacement that Mumford establishes between nomic and causal roles, would be formulated as follows: a theory of internal relations must offer an explanation of how properties can be adequately related to the things that they govern. And in order to reject this possibility, Mumford presented the following response:

An internal relation is something that exists when its relata exist. The internal relation is not, therefore, some extra element that has to be added to the relata, such as laws are supposed to be on the naïve realist account of laws or on the more sophisticated DTA theory. This is the sense in which modal properties are self-governing, therefore. (Mumford 2004, p.197)

To the extent that properties govern themselves and there is no gap through which they have to exert their influence, the difficulty of the dilemma, in Mumford's opinion, no longer arises. However, as we have indicated, Mumford believes that modal properties are self-governing, that they constitute connections between powers that are 
exhausted in those properties. But, if we accept Psillos's opinion, the causation relation would not be a purely internal relation, since it implies, at least, external spatiotemporal relations between its relata (Psillos 2006, p.261). Indeed, it is enough to remember the classic analysis of the idea of causality to realize that together with the necessary connection relation, the relations of spatial contiguity and temporal continuity between relata are required. Thus, the first horn of the dilemma would reappear, and although Mumford considers that necessary connections, and not laws, are what is required to explain regularities (Mumford 2004, p.30), his proposal does not achieve its purpose: the very same darts that he used against nomological realism now hit his own modal realism.

\section{Quasi-regularism and causal deflationism}

We have seen that regularist views, whether traditional or the more sophisticated MRL theory, fail to adequately respond to van Fraassen's challenge. The standard view not only does not allow the discrimination of genuine laws from accidental generalizations, but also flatly rejects the existence of any type of necessity in nature. MRL offers a criterion for differentiating laws from mere generalizations, but does not constitute, strictly speaking, a theory about the laws of nature (it can only be conceived as a view on the laws of science). And non-regularist conceptions, whether it is the DTA theory or Mumford's modal dispositionalism, in addition to the problems that we have underlined in each case, imply an inflationary metaphysics that not everyone would be willing to accept.

But it is possible to adopt a more ontologically modest attitude and, at the same time, overcome the problems of inference and of identification posed by van Fraassen. The proposal that we defend does justice to the regularist view (in that it does not assume any positive thesis about causality in the world), but without rejecting the existence of a foundation for regularities. Unlike Mumford's position, ours says nothing about the nature of the world's causal powers that account for observed regularities, but in opposition to traditional regularism, our proposal postulates a noumenic reality that, although inscrutable, unknowable and indescribable, stands as the basis for these regularities.

Our position takes certain insights from the position called the New Hume. According to this reading (Wright 1973; Craig 1987 and Strawson 1989), Hume did not deny that there is causality in the world; on the contrary, he thought there was. For that reason the defenders of this interpretation consider that Hume was a causal realist. However, this realism is combined with a skeptical attitude regarding the nature of causality. The followers of the New Hume rely fundamentally on certain statements of the Enquiries in which Hume apparently committed himself to the existence 
of certain causal powers that are inaccessible to our knowledge. Let us consider, by way of example only, the following two passages (Hume 1775/1748):

It must certainly be allowed, that nature has kept us at a great distance from all her secrets, and has afforded us only the knowledge of a few superficial qualities of objects; while she conceals from us those powers and principles on which the influence of these objects entirely depends. (pp.32-3)

The scenes of the universe are continually shifting, and one object follows another in an uninterrupted succession; but the power or force which actuates the whole machine, is entirely concealed from us, and never discovers itself in the sensible qualities of body. (pp.63-4)

Thus, they conclude that Hume defended a causal realism together with an epistemic skepticism. On the other hand, some authors argue against the causal realist interpretation (Blackburn 1984; Winkler 1991; Beebee 2013), and yet others consider the matter to be unsettled (Psillos 2002, p.56) and leave the question open.

It is not our goal to take a side with respect to the correct interpretation of Hume. But whatever the inscrutable intentions of the Scottish philosopher have been, the passages quoted, and others not brought up here, inspire the position that we intend to defend. We dismiss any positive theory that rides on the risky paths of modality, although we nevertheless retrieve the postulation of a certain noumenic causality (for lack of a better term) accounting for the regularities in the world. There is an inscrutable substrate, this is a metaphysically minimal presupposition from which we cannot escape.

Like Humeans, we consider scientific laws to be contingent propositions that describe observed regularities, but, distancing ourselves from them, we consider that such regularities demand an explanation. And this is where the world's noumenic aspect plays its role: causing the regularities that we observe in the world. One might think that, as Putnam pointed out regarding the Kantian noumenon, insofar as nothing can be said about it, its postulation makes no sense: the notion of a noumenal world, indicates Putnam, "is perceived to be an unnecessary metaphysical element in Kant's thought" (Putnam 1981, p.61). But recall that, immediately after stating that Kant's noumenic world is an unnecessary metaphysical assumption, he adds: "But perhaps Kant is right: perhaps we can't help thinking that there is somehow a mind-independent 'ground' for our experience even if attempts to talk about it lead at once to nonsense" (pp.61-2). Such seems to be the case of noumenic causality, that inscrutable "something" that we cannot describe but whose existence we are still inclined to recognize anyway.

Regardless of who is right about the interpretation of Hume's arguments on causality - that is, regardless of whether the classical reading of Hume's works or the one proposed by the discoverers of the New Hume is adopted — the suggestion that 
arises from the latter deserves to be taken into account. The arguments given to question the different views about causality and natural laws show that a completely satisfactory version of these concepts does not seem to have been found. However, that does not mean that we should conclude that there is no component in nature that is the one responsible for certain regularities. Perhaps, the postulation of that possibility is what pushes scientific research forward. And that would explain that a sort of confidence in the existence of causality or natural laws is part of certain presuppositions to which we must inevitably submit.

\section{References}

Armstrong, D. 1983. What is a Law of Nature? Cambridge: Cambridge University Press.

Armstrong, D. 1993. The Identification Problem and the Inference Problem. Philosophy and Phenomenological Research LIII(2): 421-22.

Ayer, A. 1963. What is a law of Nature? In: The Concept of a Person and Other Essays, pp.20934. London: Macmillan.

Borge, B. 2015. The metaphysical status of natural laws: A critique of Stephen Mumford's Nomological Antirealism. Filosofía Unisinos: 16(3): 256-69.

Beebee, H. 2013. Reply to Strawson: 'David Hume: Objects and Power'. In: S. Duncan; A. LoLordo (eds.) Debates in Modern Philosophy. Essential Readings and Contemporary Responses, pp.242-52. New York: Routledge.

Blackburn, S. 1984. Spreading the Word. Oxford, Oxford University Press.

Braithwaite, R. B. 1953. Scientific explanation; a study of the function of theory, probability and law in science. New York, NY, US: Cambridge University Press.

Carroll, J. W. 1990. The Humean Tradition. The Philosophical Review 99: 185-219.

Carroll, J. W. 1994. Laws of Nature. Cambridge: Cambridge University Press.

Craig, E. 1987. The Mind of God and the Works of Man. Oxford: Oxford University Press.

Dretske, F. I. 1977. Laws of Nature. Philosophy of Science 44: 248-68.

Ellis, B. D.; Lierse, C. E. 1994. Dispositional Essentialism. Australasian Journal of Philosophy 72: 27-45.

Gaeta, R. 2012. Causalidad, necesidad y conjunción constante en la concepción de Hume: una discusión del análisis de Psillos. In: C. S. Cibelle; L. Salvatico(eds.) Filosofia e História da Ciência no Cone Sul. Seleção de Trabalhos do 7ํEncontro da AFHIC, pp.502-09. Porto Alegre: Entrementes Editorial.

Gaeta, R.; Lucero, S. 2010. Leyes, generalizaciones accidentales y causación. In: P. García; A. Massolo (eds.) Epistemología e Historia de la Ciencia, vol. 10, 235-42. Córdoba: FFyH. UNC.

Gentile, N. 2012. Acerca de la solución de Armstrong al dilema de van Fraassen. In L. Salvatico; M. Bozzoli; L. Pesenti (eds.) Epistemología e Historia de la Ciencia, vol.18, pp.23843. Córdoba: FFyH. UNC.

Ghins, M. 2007. Laws of nature: do we need a metaphysics? Principia 11(2): 127-49.

Goodman, N. 1954. Fact, Fiction and Forecast. Harvard, Harvard University Press. 
Hume, D. 1975[1748]. Enquiries concerning Human Understanding and concerning the Principles of Morals. Ed. L. A. Selby-Bigge. Oxford: Clarendon Press.

Lewis, D. 1973. Counterfactuals. Cambridge, Massachusetts: Harvard University Press.

Mill, J. S. 1848[1843]. A System of Logic, Ratiocinative and Inductive. New York: Harper \& Brothers Publishers.

Mumford, S. 2004. Laws in Nature. London: Routledge.

Psillos, S. 2002. Causation and Explanation. Montreal \& Kingston: McGill Queen's University Press.

Psillos, S. 2006. Critical Notice: Laws in Nature. Metascience 15: 437-69.

Ramsey, F. P. 1929[1990]. General Propositions and Causality. In: D. H. Mellor (ed.) F. P. Ramsey: Philosophical Papers, pp.145-63. Cambridge: Cambridge University Press.

Strawson, G. 1989. David Hume: Objects and Powers. In: G. Strawson (2008). Real Materialism: and Other Essays, pp.416-39. Oxford: Oxford University Press.

Tooley, M. 1977. The Nature of Laws. Canadian Journal of Philosophy 7: 667-98.

van Fraassen, B. 1993. Armstrong, Cartwright, and Earman on Laws and Symmetry. Philosophy and Phenomenological Research. LIII(2): 431-44.

van Fraassen, B. 1989. Laws and Symmetry. Oxford: Oxford University Press.

Winkler, K. P. 1991. The New Hume. The Philosophical Review 100: 541-79.

Wright, J. 1973. The Sceptical Realism of David Hume. Manchester: Manchester University Press.

\section{Notes}

${ }^{1}$ For details on this issue, see Gaeta 2012.

${ }^{2}$ In recent decades an alternative interpretation of Hume, the "New Hume", has emerged, presenting him as a metaphysical realist and an epistemic skeptic. In section 5 we will return to this position in more detail.

${ }^{3}$ Psillos calls it a web-of-laws approach (Psillos 2002).

${ }^{4}$ Armstrong acknowledges that the difficulty would subsist in the case of non-causal laws, but he is optimistic to think that if such laws exist, then an explication analogous to his proposal could be given for them (Armstrong 1993, p.422).

${ }^{5}$ For details on this reply, see van Fraassen 1993.

${ }^{6}$ Mumford also refers to de re necessity as natural or metaphysical necessity.

\section{Acknowledgments}

I am very grateful to Rodolfo Gaeta and Damián Beanato for their relevant comments to the first draft of this paper. 